\title{
Review Article \\ Effects of Panax ginseng on Obesity in Animal Models: A Systematic Review and Meta-Analysis
}

\author{
Hye-Sung Park, Jae-Heung Cho, Koh-Woon Kim (D), \\ Won-Seok Chung iD, and Mi-Yeon Song iD \\ Department of Korean Rehabilitation Medicine, College of Korean Medicine, Kyung Hee University, 26 Kyungheedae-ro, \\ Dongdaemun-gu, Seoul 130-701, Republic of Korea
}

Correspondence should be addressed to Mi-Yeon Song; mysong@khu.ac.kr

Received 24 November 2017; Accepted 5 February 2018; Published 15 May 2018

Academic Editor: Juntra Karbwang

Copyright (c) 2018 Hye-Sung Park et al. This is an open access article distributed under the Creative Commons Attribution License, which permits unrestricted use, distribution, and reproduction in any medium, provided the original work is properly cited.

Objective. To determine the antiobesity effects of Panax ginseng in animals. Methods. We conducted a systematic search for all controlled trials (up to March 2017) that assessed the antiobesity effects of $P$. ginseng in animal obesity models in the PubMed, EMBASE, Cochrane library, Web of Science, and Scopus databases. The primary outcome was final body weight measured at the longest follow-up time after administration of the intervention. The secondary outcome was the lipid profile. We assessed methodological quality using the SYRCLE risk of bias tool, and RevMan 5.3 was used to perform a meta-analysis. Finally, a subgroup analysis of parameters including intervention duration, animal models, and type of ginseng was performed. Result. We identified 16 studies that met the inclusion criteria. Data from the meta-analysis indicated that the intervention group had a significantly lower body weight than the control group (SMD: $-1.50,95 \% \mathrm{CI}:-1.90$ to $-1.11, \chi^{2}: 78.14, P<0.0001, I^{2}=58 \%$ ). Final body weight was lower in an animal obesity model induced by high-fat diet than in genetic models. Also the intervention group had a significantly higher serum HDL level and lower serum LDL, TG, and TC level than the control group. Conclusion. Our meta-analysis indicated that oral administration of $P$. ginseng significantly inhibits weight gain and improves serum lipid profiles in animal obesity models. However, causes of obesity and type of ginseng may affect treatment effects.

\section{Introduction}

The worldwide prevalence of obesity has increased significantly in recent decades [1]. Obesity is associated with not only the development of various chronic diseases [2], but also the increased risk of mortality [3]. As a result, obesity is considered a human health priority and a critical health issue requiring both prevention and treatment [4]. The treatment of obesity using conventional medication has numerous limitations, including adverse effects of medication and the potential for drug abuse $[5,6]$. Therefore, interest in complementary and alternative therapies for the treatment of obesity has been increasing globally $[7,8]$.

The Greek word panax means "cure-all" [9]. As its name implies, Panax ginseng has been shown to exert several pharmacological and physiological effects. These include beneficial effects against cancer [10], hypertension [11], diabetes
[12], nociception [13], and stroke [14], as well as reported improvements in chronic fatigue [15]. Furthermore, it has also been reported to exert antiobesity effects $[16,17]$.

Previous studies have reported various mechanisms for the antiobesity effect of $P$. ginseng in animal models. These mechanisms include the reduction of the intestinal absorption of dietary fat via inhibition of pancreatic lipase activity [18], regulation of the hypothalamic expression of orexigenic neuropeptide $Y$ and anorexigenic cholecystokinin [19, 20], facilitation of lipoprotein lipase, and regulation of the PPAR$\gamma$ signaling pathway [21,22].

However, the complex relationship between $P$. ginseng and its antiobesity effects has not yet been established under in vivo conditions. Although $P$. ginseng and its components have been shown to exert antiobesity effects by modulating physiological lipid metabolism in vivo or via intracellular signaling in numerous preclinical studies [23], the results are far from conclusive. 
Furthermore, although $P$. ginseng has been shown to exert antiobesity effects in several animal studies, there have been relatively few studies investigating its effects in human obesity $[17,24,25]$. Systematic reviews and meta-analyses of animal studies can yield useful information for the design of subsequent human clinical studies [26]. Several recent studies $[17,27,28]$ have reviewed the antiobesity effect of ginseng, but reported only descriptive outcomes and mechanism of action without quantitatively analyzing the data. Therefore, a systematic review and meta-analysis are required to comprehensively examine the antiobesity effects of ginseng in animal models, which, to the best of our knowledge, has not been reported to date. We therefore conducted a systematic review and meta-analysis to determine the antiobesity effects of $P$. ginseng in animals.

\section{Methods}

We conducted a systematic review according to the Cochrane method [29] and SYRCLE guideline [30]. The results are reported in accordance with PRISMA guidelines [31]. The protocol for this review was registered on the Collaborative Approach to Meta-Analysis and Review of Animal Data from Experimental Studies website (http://www.camarades.info).

\subsection{Inclusion Criteria for Studies}

2.1.1. Types of Studies. We included controlled comparative studies assessing the effect of $P$. ginseng in preclinical models of obesity in vivo. Review articles, observational studies, human studies, and in vitro studies were excluded. Studies published in English were included. There were no restrictions on publication date or publication status.

2.1.2. Types of Subjects. Genetic, physiological, epigenetic, and environmental animal models of obesity [32-36] were included in this study. Each model represented at least one of the diverse pathophysiological characteristics of obesity. With consideration to our proposed future clinical trials on adult obesity, neonatal animal models of obesity were excluded due to the existence of potential differences in the underlying mechanisms and the response to a specific treatment between adults and neonates. For the same reason, animal models with other diseases, such as cancer and type I diabetes, were excluded. The comparison groups included sham-controlled animals or animals with preclinically induced obesity without any intervention.

2.1.3. Types of Interventions. The intervention group included animals from studies that investigated the antiobesity effect of $P$. ginseng. Although numerous variants of gichonseng have many of the same compounds and medicinal properties, we focused on $P$. ginseng C.A. Meyer (Korean ginseng). Other types of ginseng, such as Panax quinquefolius (American ginseng), Panax japonicas, Panax notoginseng, and Panax trifolius, were excluded. Studies using roots of $P$. ginseng were included, but those using berries or leaves were excluded. Only oral administrations of ginseng were included, while administration by other routes such as intravenous, intramuscular, and intraperitoneal was excluded. Furthermore, studies using only individual substances extracted from ginseng, such as ginsenosides or compound $\mathrm{K}$, were excluded. The majority of processing or extractions methods routinely used in clinical practice were included, such as white ginseng, red ginseng, fermented red ginseng, black ginseng, water extraction, ethanol extraction, vinegar extraction, powdered, and high-pressure extraction. Other processing or extracting methods not commonly used, such as those employing pectin, enzymes, or carbon dioxide, were excluded. Cointervention studies including coadministration with other compounds, herbs, formula, or nonoral preparations and studies in combination with exercise were excluded to avoid confounding factors. For inclusion in our analysis, P. ginseng must have been administered during or following the induction of experimental obesity. Experiments using $P$. ginseng without the induction of obesity were excluded, as our objective was to identify preventive or treatment effects for obesity. [37]

\subsubsection{Types of Outcome Measurements}

(1) Primary Outcome. The primary outcome was final body weight (BW) measured at the longest follow-up time after administration of the intervention.

(2) Secondary Outcomes. Secondary outcome measures included lipid profiles such as triacylglycerol (TG), total cholesterol (TC), high-density lipoprotein (HDL), and lowdensity lipoprotein (LDL). For inclusion in the meta-analysis, the exact animal numbers in each group, the mean effect size, and the variance of the outcomes were required to have been reported.

2.2. Search Methods for Identification of Studies. We identified studies on the antiobesity effect of $P$. ginseng in animal models from the following databases in consultation with an experienced medical information-scientist or librarian: PubMed, Embase, Web of Science, Cochrane Library, and Scopus. Searches were performed until March 2017. There was no language restriction. A search strategy for PubMed (Table 1) was developed with guidance $[29,38]$. Animal filters validated for PubMed/MEDLINE and Embase were used to enhance the search efficiency with respect to identifying all animal studies $[39,40]$.

\subsection{Data Collection and Analysis}

2.3.1. Study Selection. Two reviewers independently reviewed and determined the eligibility of studies. Disagreements between investigators were resolved by consensus after discussion. Duplicates and nonexperimental studies were removed by screening the titles and abstracts. Reviewers carefully examined the full text of studies where it was unclear whether the studies met the inclusion criteria. Studies were excluded if they involved any unqualified interventions. Study selection is summarized in a PRISMA flow diagram [31] (Figure 1).

2.3.2. Data Extraction and Management. We extracted the following data from selected studies: study characteristics 
TABle 1: PubMed search strategy.

\begin{tabular}{|c|c|}
\hline History & Search string \\
\hline$\# 1$ & obesity $[\mathrm{MeSH}$ terms] \\
\hline \#2 & $\begin{array}{l}\text { obes }^{*}\left[\text { tiab] OR adipos* }{ }^{*} \text { tiab] OR body mass index [tiab] OR BMI[tiab] OR Overweight[tiab] OR Body }\right. \\
\text { weight[tiab] OR Body size[tiab] OR Body constitution[tiab] OR weight gain[tiab] OR Fat mass[tiab] OR } \\
\text { percent fat[tiab] OR Leptin[tiab] OR Grehlin[tiab] OR energy expenditure[tiab] }\end{array}$ \\
\hline \#3 & $\# 1 \mathrm{OR} \# 2$ \\
\hline$\# 4$ & $\operatorname{panax}[\mathrm{MeSH}$ terms $]$ \\
\hline$\# 5$ & $\begin{array}{l}\text { Panax ginseng[tiab] OR ginseng[tiab] OR panax[tiab] OR red ginseng[tiab] OR Korean red ginseng[tiab] OR } \\
\text { ginsan[tiab] OR “jen shen"[tiab] OR shinseng[tiab] OR "ren shen"[tiab] OR schinseng[tiab] OR ninjin[tiab] }\end{array}$ \\
\hline \#6 & $\# 4 \mathrm{OR} \# 5$ \\
\hline \#7 & "animal experimentation" [MeSH terms] \\
\hline$\# 8$ & animals filter (Hooijmans et al. [40]) \\
\hline \#9 & $\# 7 \mathrm{OR} \# 8$ \\
\hline$\# 10$ & \#3 AND \#6 AND \#9 \\
\hline
\end{tabular}

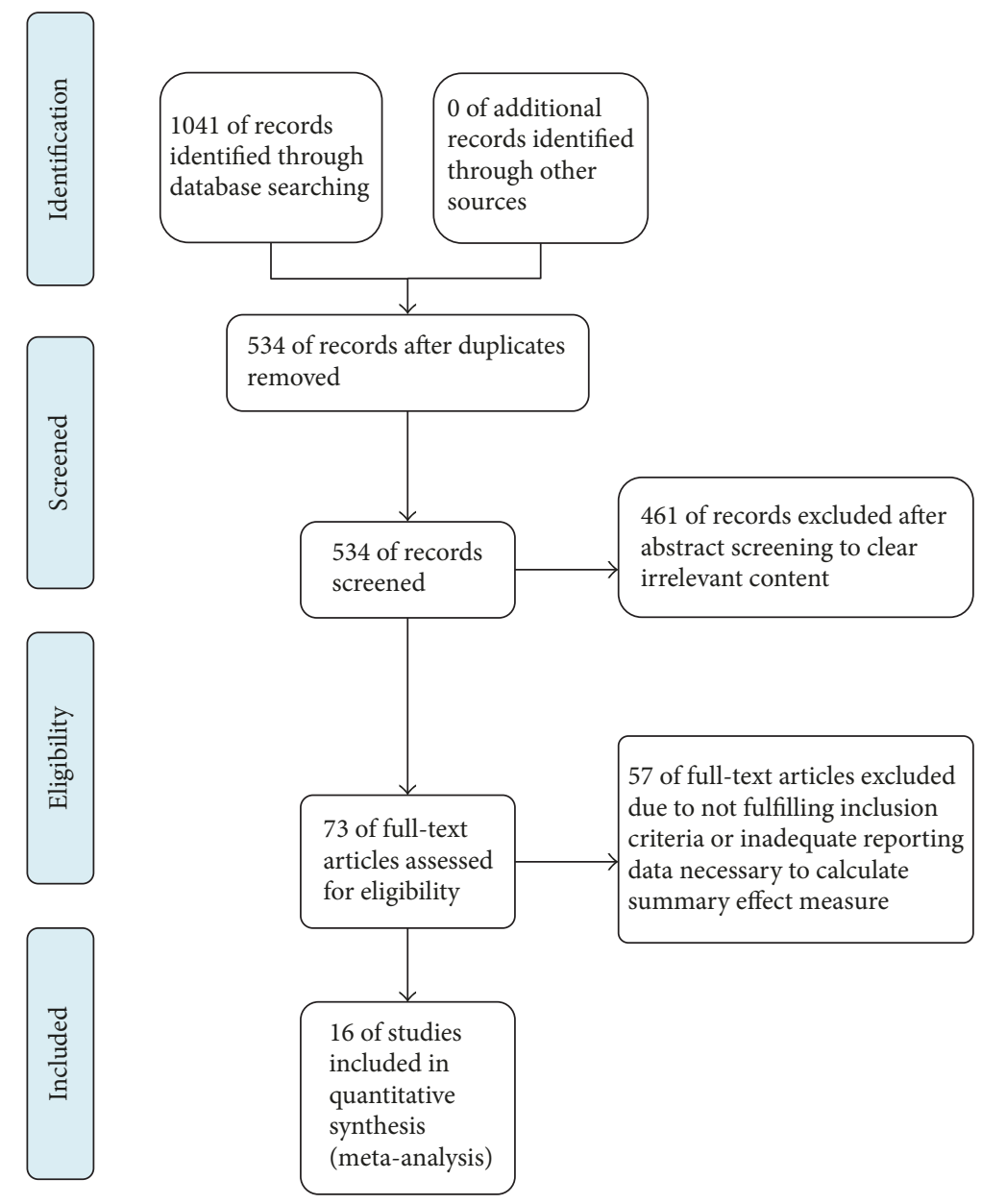

FIgURE 1: PRISMA flow diagram for study search process.

(study title, journal published, author, and publication date); study population (animal age, gender, strain, and type of obesity model); intervention and comparison (dose and duration of intervention, description of preparation and suspension of $P$. ginseng, and number of animals); and outcome measures (final body weight and lipid profiles including TG, TC, LDL, and HDL).

Information not available from the manuscript was requested from the first or corresponding author by email. Data were independently assessed and extracted by two 
reviewers using standardized extraction forms. Extracted data were reviewed by a third researcher, and discrepancies were adjudicated by the arbitrator.

2.3.3. Assessment of Risk of Bias in Included Studies. The methodological quality of individual studies was assessed according to the SYRCLE risk of bias (RoB) tool for animal studies [41]. Two authors independently assessed the risk of bias of the included studies according to SYRCLE RoB tool, which evaluates the following domains with three outcomes ("low risk," "high risk," or "unclear risk"): sequence generation (selection bias), baseline characteristics (selection bias), allocation concealment (selection bias), random housing (performance bias), blinding of personnel and outcome assessors (performance and detection bias), random outcome assessment (detection bias), incomplete outcome data (attrition bias), and selective outcome reporting (reporting bias). A third author was consulted to resolve discrepancies related to risk of bias.

2.3.4. Measures of Treatment Effect. As outcomes were measured in diverse species, the standardized mean difference (SMD) was used to measure treatment effect with $95 \%$ confidence intervals (CIs). The meta-analysis focused not on precise estimates, but on the direction of the outcome because of the expected heterogeneity in animal study characteristics (e.g., significant variations in species or intervention protocols).

2.3.5. Handling Missing Data. The reviewers attempted to obtain the pertinent information by contacting the first or corresponding authors by email where relevant data were missing. If the required data were not obtained, the study was excluded from the analysis.

2.3.6. Assessment of Heterogeneity. To determine whether the included studies had sufficient homogeneity for metaanalysis, we determined between-study heterogeneity by calculating $I^{2}$ inconsistency values. We analyzed the statistical heterogeneity using a $\chi^{2}$ test $(P$ value $<0.10)$ and quantified it using $I^{2}$ and $T^{2}$ statistics. Heterogeneity was regarded as substantial where $I^{2}>50 \%, T^{2}>0$, or the $P$ value < 0.10 . Heterogeneity was defined according to the $I^{2}$ range: $0 \%-40 \%$ indicated no important heterogeneity, 40\%-60\% moderate heterogeneity, $60 \%-90 \%$ substantial heterogeneity, and $>90 \%$ considerable heterogeneity [42].

2.3.7. Assessment of Publication Bias. A graphical funnel plot was used to investigate whether publication bias was present in the studies included in the review [43].

2.3.8. Data Synthesis. A meta-analysis was performed using Review Manager 5.3 software. A random-effects model was used in the analysis because of the expected diversity among animal studies

If the number of treatment groups was more than two, control groups were shared and represented more than once in the summary estimates calculation. To avoid this, the number of animals in the control group was adjusted by dividing the total number of control animals by the number of comparisons ( $N$ of total/ $N$ of treatment group) [44].

2.3.9. Subgroup Analysis and Investigation of Heterogeneity. Subgroup analysis, including analysis of the intervention duration, animal models, and type of ginseng, was performed.

\section{Results}

\subsection{Description of Studies}

3.1.1. Search Results. A flow chart of the study selection process is presented in a PRISMA flow diagram (Figure 1). We identified 1041 publications. After duplicates were removed, 534 studies remained. Based on the inclusion criteria, 461 studies were excluded following the screening of titles and abstracts. The full texts of the remaining 73 publications were reviewed, and 40 that did not meet the inclusion criteria were excluded. As a result, 33 studies that met the inclusion criteria were reviewed. A further 17 studies were excluded for inadequate reporting of data necessary to calculate the summary effect. Finally, 16 studies were included in the meta-analysis, all of which had been published between 2004 and 2016 .

3.1.2. Included Studies. Data pertaining to 426 animals from 16 studies were analyzed. The characteristics of the included studies are shown in Table 2. Twelve studies used acquired obesity animal models induced by a high-fat diet (HFD): four were in Sprague-Dawley (SD) rats, three were in C57BL/6J mice, one was in Wistar rats, and four were in Institute for Cancer Research (ICR) mice. For genetic obesity models, three studies used leptin receptor-deficient $(\mathrm{db} / \mathrm{db})$ mice and one study used Otsuka Long Evans Tokushima Fatty (OLEFT) rats. Sample size per group ranged from 5 to 10 animals. The duration of administration of $P$. ginseng ranged from 8 to 14 weeks. Various methods of extraction and processing were described: red ginseng (RG), fermented red ginseng (FRG), white ginseng (WG), black ginseng (BG), ginsam; vinegar extracted (GS, VE), water extracted (WE), high-pressure extracted (PE), and ethanol extracted (EE).

3.1.3. Excluded Studies. Following the full-text manuscript review, 57 studies were excluded for failing to fulfill the inclusion criteria or having inadequate reporting data necessary to calculate the summary effect.

3.2. Risk of Bias in Included Studies. The SYRCLE RoB tool for animal studies [41] was used to assess the risk of bias in the included 16 studies. The risk of bias for each study is summarized in Figure 2. As for most animal studies [60], the studies included in this review contained insufficient reporting of the experimental details. As a result, several studies were judged as having an "unclear risk of bias." Allocation concealment; blinding of caregivers, investigators, or outcome assessors; and random outcome assessment were incompletely described in most studies. However, baseline characteristics, incomplete outcome data, and selective reporting were factors associated with a low risk of bias. Baseline characteristics, such as sex, age, and initial weight, 
TABLE 2: Summary of included studies.

\begin{tabular}{|c|c|c|c|c|c|c|c|c|c|}
\hline Study & $\begin{array}{c}\text { Animal } \\
\text { model }\end{array}$ & Sex & $\begin{array}{c}\text { Age } \\
\text { (weeks) }\end{array}$ & $\begin{array}{l}\text { Weight } \\
\text { (g) }\end{array}$ & $\begin{array}{l}N \text { per } \\
\text { group }\end{array}$ & $\begin{array}{l}\text { Material } \\
\text { (extraction } \\
\text { method) }\end{array}$ & $\begin{array}{c}\text { Dose or } \\
\text { concentration }\end{array}$ & $\begin{array}{l}\text { Duration } \\
\text { (weeks) }\end{array}$ & Outcome \\
\hline $\begin{array}{l}\text { Chung et al. } \\
2016[45]\end{array}$ & $\begin{array}{l}\text { C57BL/6N } \\
\text { mice with } \\
\text { HFD }\end{array}$ & M & 4 & 12 & 8 & $\begin{array}{l}\text { (1) RG (WE) } \\
\text { (2) WG (WE) } \\
\text { (3) AG4 (WE) } \\
\text { (4) AG5(WE) }\end{array}$ & Unknown & 8 & $\begin{array}{c}\text { BW, HDL, TC, } \\
\text { TG }\end{array}$ \\
\hline $\begin{array}{l}\text { Han et al. } 2008 \\
{[46]}\end{array}$ & $\mathrm{db} / \mathrm{db}$ mice & M & 5 & $25-26$ & 5 & GS (VE) & $\begin{array}{l}\text { (1) } 300 \mathrm{mg} / \mathrm{kg} \\
\text { (2) } 500 \mathrm{mg} / \mathrm{kg}\end{array}$ & 8 & BW, HDL \\
\hline $\begin{array}{l}\text { Hong et al. } 2013 \\
\text { [47] }\end{array}$ & $\mathrm{db} / \mathrm{db}$ mice & M & 8 & $25-26$ & 10 & RG (WE) & $\begin{array}{l}\text { (1) } 100 \mathrm{mg} / \mathrm{kg} \\
\text { (2) } 200 \mathrm{mg} / \mathrm{kg}\end{array}$ & 8 & BW, HDL \\
\hline $\begin{array}{l}\text { Jung et al. } 2014 \\
\text { [48] }\end{array}$ & $\begin{array}{c}\text { SD rat } \\
\text { with HFD }\end{array}$ & M & 3 & $78-110$ & 10 & $\begin{array}{l}\text { (1) WG (PE) } \\
\text { (2) WG (WE) }\end{array}$ & $\begin{array}{l}\text { (1) } 1500 \mathrm{mg} / \mathrm{kg} \\
\text { (2) } 1500 \mathrm{mg} / \mathrm{kg}\end{array}$ & 14 & $\begin{array}{l}\text { BW, HDL, } \\
\text { LDL, TC, TG }\end{array}$ \\
\hline $\begin{array}{l}\text { Jung et al. } 2015 \\
\text { [49] }\end{array}$ & $\begin{array}{c}\text { SD rat } \\
\text { with HFD }\end{array}$ & M & Unknown & $80-110$ & 8 & RG (PE) & $1500 \mathrm{mg} / \mathrm{kg}$ & 14 & $\begin{array}{l}\text { BW, HDL, } \\
\text { LDL, TC, TG }\end{array}$ \\
\hline $\begin{array}{l}\text { Kho et al. } 2016 \\
{[50]}\end{array}$ & $\begin{array}{c}\text { SD rat } \\
\text { with HFD }\end{array}$ & M & 7 & $270-280$ & 10 & $\begin{array}{l}\text { (1) FRG (WE) } \\
\text { (2) RG (WE) }\end{array}$ & $\begin{array}{l}\text { (1) } 250 \mathrm{mg} / \mathrm{kg} \\
\text { (2) } 250 \mathrm{mg} / \mathrm{kg}\end{array}$ & 8 & $\begin{array}{l}\text { BW, HDL, } \\
\text { LDL, TC, TG }\end{array}$ \\
\hline $\begin{array}{l}\text { Kim et al. } 2013 \\
{[51]}\end{array}$ & $\begin{array}{l}\text { ICR mice } \\
\text { with HFD }\end{array}$ & $\mathrm{F}$ & 6 & $80-110$ & 10 & $\begin{array}{c}\text { (1) (3) FRG } \\
\text { (WE) } \\
\text { (4) } \mathrm{RG}(\mathrm{WE})\end{array}$ & $\begin{array}{l}\text { (1) } 125 \mathrm{mg} / \mathrm{kg} \\
\text { (2) } 250 \mathrm{mg} / \mathrm{kg} \\
\text { (3) } 500 \mathrm{mg} / \mathrm{kg} \\
\text { (4) } 250 \mathrm{mg} / \mathrm{kg}\end{array}$ & 12 & $\begin{array}{l}\text { BW, HDL, } \\
\text { LDL, TC, TG }\end{array}$ \\
\hline $\begin{array}{l}\text { Lee et al. } 2014 \\
\text { [52] }\end{array}$ & $\begin{array}{l}\text { Aged SD rat } \\
\text { with HFD }\end{array}$ & M & 8 & $200-250$ & 8 & RG (WE) & $200 \mathrm{mg} / \mathrm{kg}$ & 8 & $\begin{array}{l}\text { BW, HDL, } \\
\text { LDL, TC, TG }\end{array}$ \\
\hline $\begin{array}{l}\text { Lee et al. } 2013 \\
{[53]}\end{array}$ & $\begin{array}{c}\text { C57BL/6N } \\
\text { mice with } \\
\text { HFD }\end{array}$ & M & 6 & 12 & 8 & $\mathrm{BG}(\mathrm{EE})$ & $\begin{array}{l}\text { (1) } 1 \% \\
\text { (2) } 3 \% \\
\text { (3) } 5 \%\end{array}$ & 12 & $\begin{array}{c}\text { BW, HDL, TC, } \\
\text { TG }\end{array}$ \\
\hline $\begin{array}{l}\text { Lee et al. } 2010 \\
\text { [54] }\end{array}$ & $\begin{array}{l}\text { ICR mice } \\
\text { with HFD }\end{array}$ & $\mathrm{F}$ & 4 & $23-24$ & 8 & WG (EE) & $\begin{array}{l}\text { (1) } 0.8 \% \\
\text { (2) } 1.6 \%\end{array}$ & 8 & $\begin{array}{c}\text { BW, HDL, TC, } \\
\text { TG }\end{array}$ \\
\hline $\begin{array}{l}\text { Lim et al. } 2009 \\
\text { [55] }\end{array}$ & OLETF rat & M & 5 & $78-110$ & 8 & GS (VE) & $\begin{array}{l}\text { (1) } 300 \mathrm{mg} / \mathrm{kg}(/ \text { day }) \\
\text { (2) } 500 \mathrm{mg} / \mathrm{kg}(/ \text { day })\end{array}$ & 8 & $\begin{array}{c}\text { BW, HDL, } \\
\text { LDL, TC, TG }\end{array}$ \\
\hline $\begin{array}{l}\text { de Miranda- } \\
\text { Henriques et al. } \\
2014 \text { [56] }\end{array}$ & $\begin{array}{l}\text { Wistar rat } \\
\text { with HFD }\end{array}$ & Unknown & 8 & $200-250$ & 10 & WG (unknown) & $100 \mathrm{mg} / \mathrm{kg}$ & 8 & $\begin{array}{l}\text { BW, HDL, } \\
\text { LDL, TC, TG }\end{array}$ \\
\hline $\begin{array}{l}\text { Park et al. } 2005 \\
\text { [57] }\end{array}$ & $\mathrm{db} / \mathrm{db}$ mice & M & 4 & $20-30$ & 10 & RG (P) & $0.5 \%$ & 12 & BW, TG \\
\hline $\begin{array}{l}\text { Song et al. } 2012 \\
\text { [23] }\end{array}$ & $\begin{array}{l}\text { C57BL/6J } \\
\text { mice with } \\
\text { HFD }\end{array}$ & M & 4 & $200-250$ & 10 & RG (EE) & $\begin{array}{l}\text { (1) } 500 \mathrm{mg} / \mathrm{kg} \\
\text { (2) } 1000 \mathrm{mg} / \mathrm{kg} \\
\text { (3) } 3000 \mathrm{mg} / \mathrm{kg}\end{array}$ & 13 & $\begin{array}{l}\text { BW, HDL, } \\
\text { LDL, TC, TG }\end{array}$ \\
\hline $\begin{array}{l}\text { Yun et al. } 2004 \\
\text { [58] }\end{array}$ & $\begin{array}{l}\text { ICR mice } \\
\text { with HFD }\end{array}$ & M & 5 & $\begin{array}{l}\text { approx. } \\
25\end{array}$ & 8 & WG (EE) & $\begin{array}{l}\text { (1) } 250 \mathrm{mg} / \mathrm{kg} \\
\text { (2) } 500 \mathrm{mg} / \mathrm{kg}\end{array}$ & 8 & $\begin{array}{l}\text { BW, HDL, } \\
\text { LDL, TC, TG }\end{array}$ \\
\hline $\begin{array}{l}\text { Yun et al. } 2007 \\
\text { [59] }\end{array}$ & $\begin{array}{l}\text { ICR mice } \\
\text { with HFD }\end{array}$ & M & 5 & $18-20$ & 8 & $\begin{array}{l}\text { (1) GS (VE) } \\
\text { (2) WG (EE) }\end{array}$ & $\begin{array}{l}\text { (1) } 500 \mathrm{mg} / \mathrm{kg} \\
\text { (2) } 500 \mathrm{mg} / \mathrm{kg}\end{array}$ & 8 & $\begin{array}{l}\text { BW, HDL, } \\
\text { LDL, TC, TG }\end{array}$ \\
\hline
\end{tabular}

FRG: fermented red ginseng, RG: red ginseng, BG: black ginseng, GS: ginsam (vinegar extracted ginseng), WG: white ginseng, EE: ethanol extracted, WE: water extracted, PE: high pressure extracted, P: powdered, VE: vinegar extracted, AG4: 4-year-old fresh ginseng, AG5: 5-year-old fresh ginseng BW: body weight, HDL: high-density lipoprotein, LDL: low-density lipoprotein, $N$ : number, and db/db mice: the leptin receptor-deficient mouse. Lep ${ }^{\mathrm{db}} / \mathrm{Lep}^{\mathrm{db}}$ mouse, $^{\mathrm{d}}$ the "diabetic" mouse, ICR mice: Institute for Cancer Research mice, OLEFT rat: Otsuka Long Evans Tokushima Fatty rat, SD rats: Sprague-Dawley rats, HFD: high-fat diet, TC: total cholesterol, and TG: triacylglycerol.

were described and revealed to have no significant difference between the intervention and control groups. Compared with human randomized controlled trials, randomization, concealment of allocation, and blinding of investigators and outcome assessors are not yet standardized in animal studies [60].

\subsection{Effects of Interventions}

3.3.1. Primary Outcome: Final Body Weight. The effect of $P$. ginseng on final BW was evaluated, and 16 studies reported this outcome. The mean final BW of groups treated with P. ginseng administration was significantly less than that of control groups (SMD $=-1.50,95 \% \mathrm{CI}-1.90$ to -1.11 ; Figure 3 ). The heterogeneity was determined as moderate $\left(\chi^{2}=78.14\right.$, $\left.P<0.0001, I^{2}=58 \%\right)$.

(1) P. ginseng Processing and Extraction Method. Subgroup analysis according to the type of $P$. ginseng preparation was performed (Figures 3 and 6(f)). The nine subgroup variables were GS (VE), WG (EE), WG (WE), RG (WE), RG (EE), FRG 


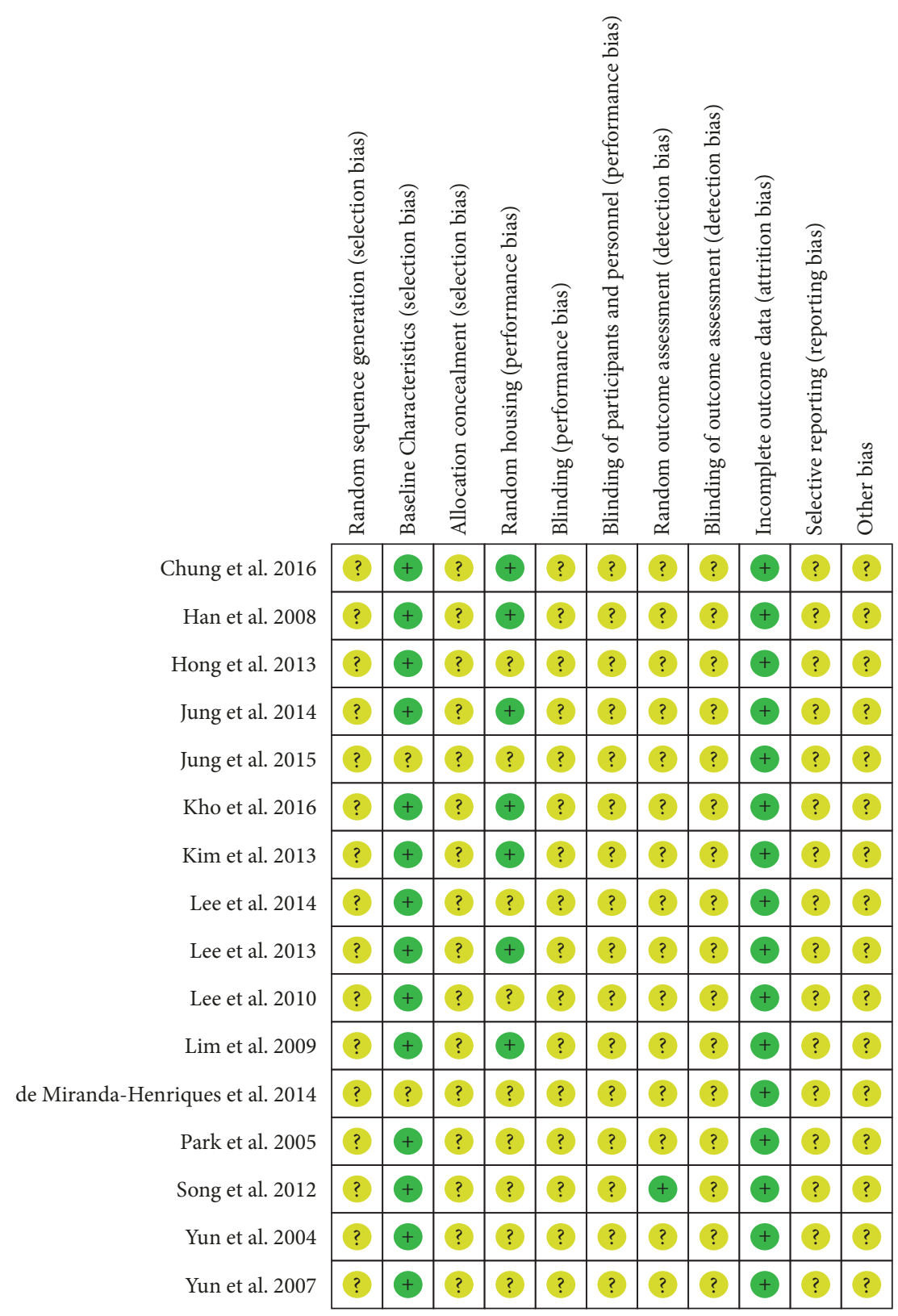

FIGURE 2: Risk of bias summary for the 16 included studies.

(WE), RG (PE), WG (PE), and VG (EE). Heterogeneity was found to be partially decreased. Furthermore, subgroup analysis for processing and extracting methods for P. ginseng were performed independently (Figures 6(d) and 6(e)), with the former being shown to affect heterogeneity while extraction method did not significantly affect heterogeneity.

(2) Animal Obesity Models. Subgroup analysis was performed according to the animal obesity models used in the selected studies (Figures 4 and 6). The subgroup variables included aged SD rats, SD rats, C57BL/6J mice, ICR mice, Wistar rats, $\mathrm{db} / \mathrm{db}$ mice, and OLEFT rats, and the type of animal obesity model was found to be a factor affecting heterogeneity.
Following subgroup analysis according to animal model, the treatment effect size was found to be significantly higher in acquired obesity animal models induced by HFD (SMD = $-1.79,95 \%$ CI -2.23 to $-1.34, I^{2}=52 \%$ ) than in genetic animal obesity models (SMD $=-0.55,95 \% \mathrm{CI}-1.12$ to $0.03, I^{2}=35 \%$ ). Particularly for the $\mathrm{db} / \mathrm{db}$ mouse genetic model of obesity, no significant treatment effect was observed $(\mathrm{SMD}=-0.21,95 \%$ $\mathrm{CI}=-1.80$ to $\left.-1.04, I^{2}=0 \%\right)$.

(3) Duration of $P$. ginseng Administration. Subgroup analysis was performed according to the duration of treatment with $P$. ginseng (Figures 5 and 6(c)), grouped by interventions for 8 weeks, or more than 8 weeks. However, no significant 


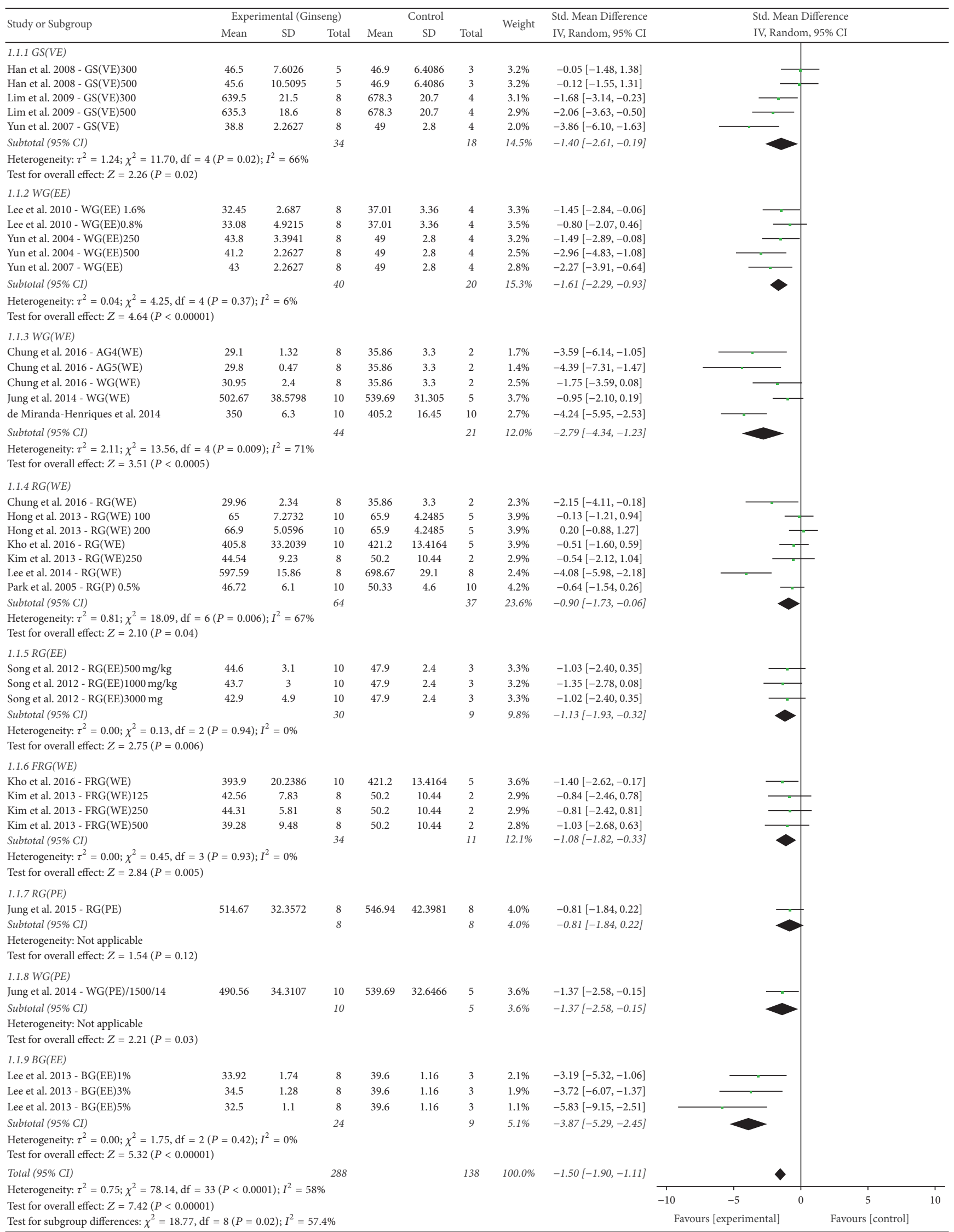

FIGURE 3: Forest plot and subgroup analysis comparing body weight between the treatment and control groups according to P. ginseng processing status and extraction method. FRG: fermented red ginseng; RG: red ginseng; BG: black ginseng; GS: ginsam (vinegar extracted ginseng); WG: white ginseng; EE: ethanol extracted; WE: water extracted; PE: high-pressure extracted; P: powdered; VE: vinegar extracted. 


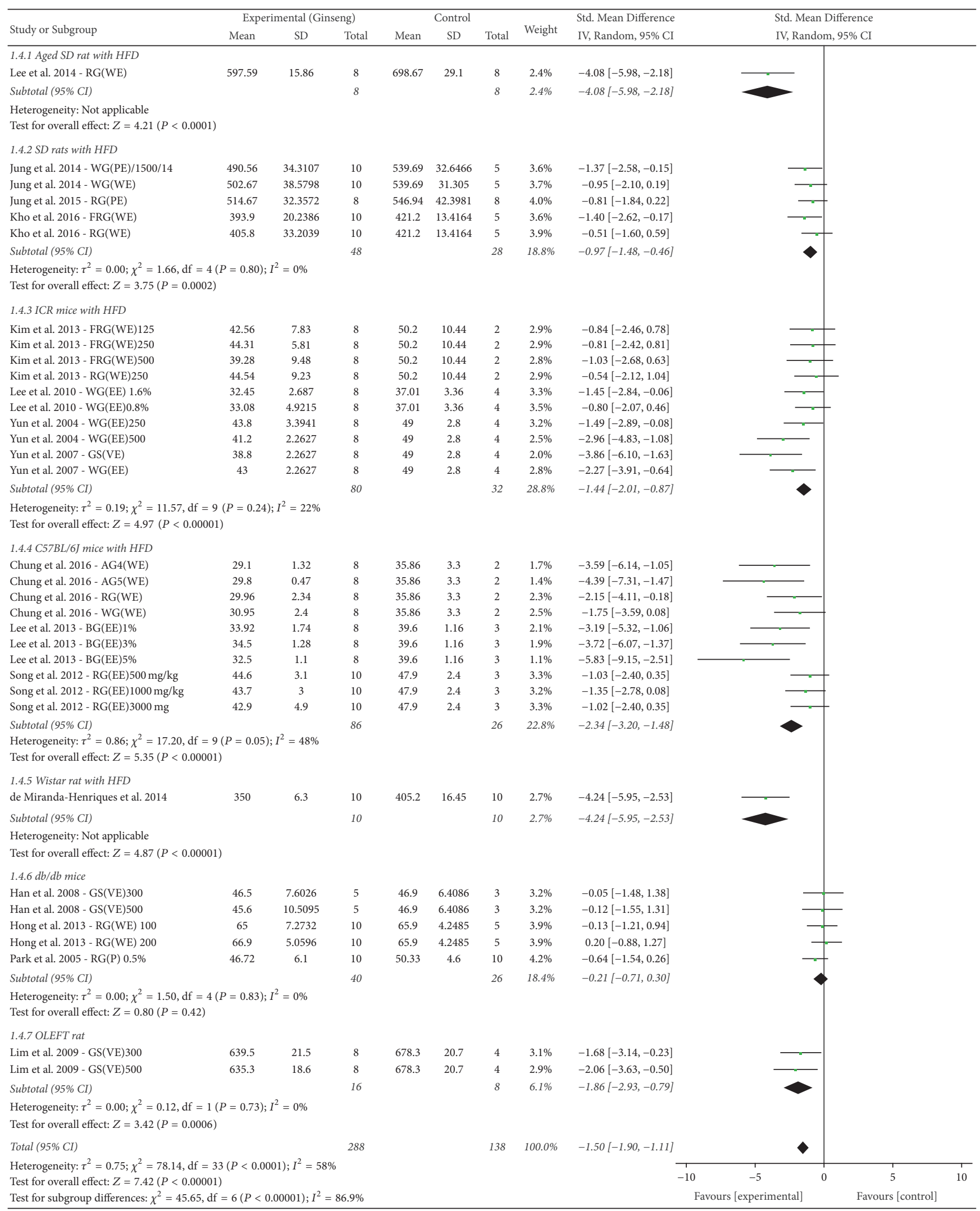

FIGURE 4: Forest plot and subgroup analysis comparing body weight between the treatment and control groups according to animal obesity model. FRG: fermented red ginseng, RG: red ginseng, BG: black ginseng, GS: ginsam (vinegar extracted ginseng), WG: white ginseng, EE: ethanol extracted, WE: water extracted, PE: high-pressure extracted, VE: vinegar extracted, AG4: 4-year-old fresh ginseng, AG5: 5-year-old fresh ginseng, and $\mathrm{db} / \mathrm{db}$ mice: the leptin receptor-deficient mouse. Lep ${ }^{\mathrm{db}} /$ Lep $^{\mathrm{db}}$ mouse, the "diabetic" mouse, ICR mice: Institute for Cancer Research mice, OLEFT rat: Otsuka Long Evans Tokushima Fatty rat, SD rats: Sprague-Dawley rats, and HFD: high-fat diet. 


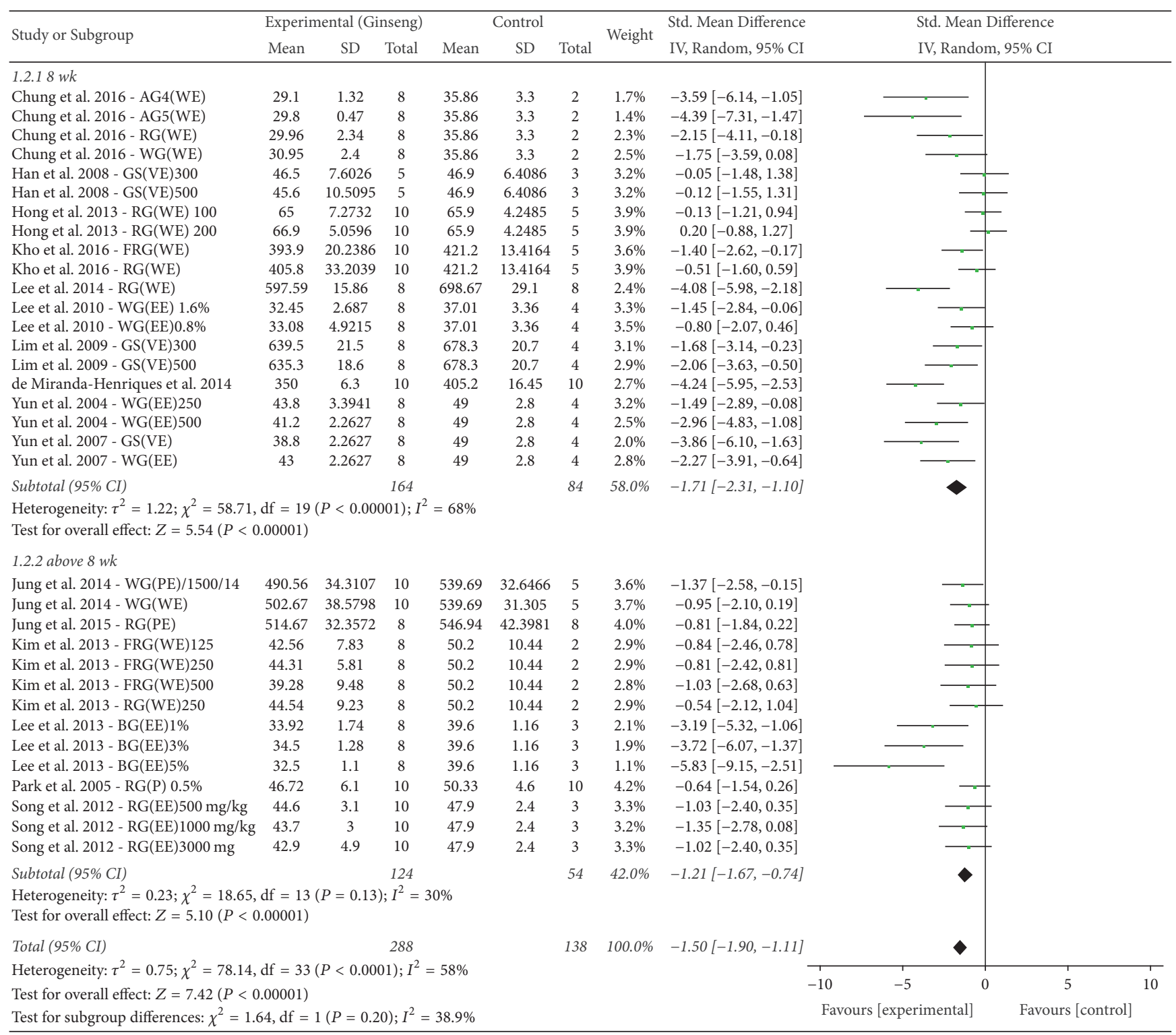

FIGURE 5: Forest plot and subgroup analysis comparing body weight between the treatment and control groups according to duration of $P$. ginseng administration. AG4: 4-year-old ginseng, FRG: fermented red ginseng, RG: red ginseng, BG: black ginseng, GS: ginsam (vinegar extracted ginseng), WG: white ginseng, EE: ethanol extracted, WE: water extracted, PE: high-pressure extracted, P: powdered, and VE: vinegar extracted.

difference in effect size was observed between the two groups.

\subsubsection{Secondary Outcomes}

(1) HDL. The effect of $P$. ginseng on HDL was evaluated among the 11 studies that reported this outcome. The mean final HDL in the experimental groups was significantly higher than that in the control groups (SMD $=1.78,95 \%$ CI 1.14 to 2.42 ), with substantial heterogeneity $\left(I^{2}=72 \%, \chi^{2}=74.28, P<0.00001\right)$ (Figure 7).

(2) LDL. The effect of $P$. ginseng on LDL was evaluated among the 8 studies that reported this outcome. The mean LDL of the experimental groups was significantly lower than that of the control groups ( $\mathrm{SMD}=-3.16,95 \% \mathrm{CI}=-4.44$ to -1.87 ; $P<0.00001)$, with substantial heterogeneity $\left(I^{2}=86 \%, \chi^{2}=\right.$ 84.91, $P<0.00001$ ) (Figure 8).

(3) TG. The effect of $P$. ginseng on TG was evaluated among the 13 experiments reported this outcome. The mean TG of the experimental groups was significantly lower than that of the control groups (SMD $=-2.00,95 \% \mathrm{CI}=-2.56$ to -1.45 ; $P<0.00001)$, with substantial heterogeneity $\left(I^{2}=68 \%, \chi^{2}=\right.$ 74.08, $P<0.00001$ ) (Figure 9).

(4) TC. The effect of $P$. ginseng on TC was evaluated among the 13 experiments that reported this outcome. The mean TC 


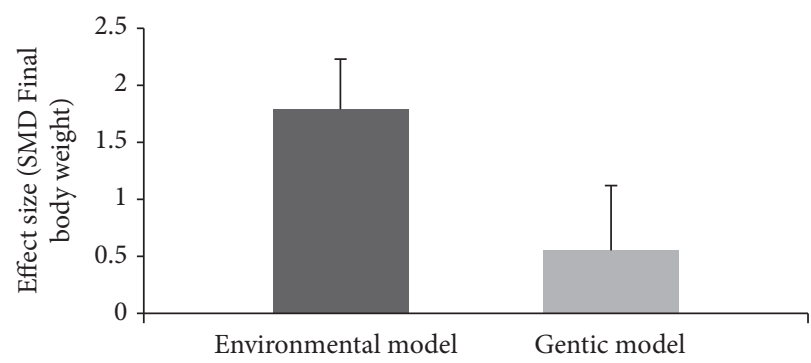

(a)

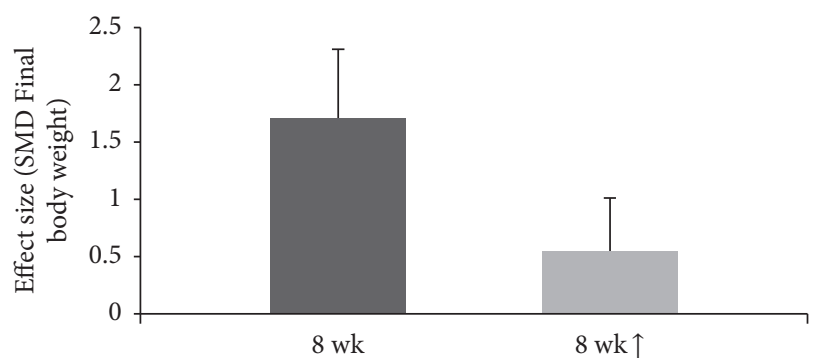

(c)

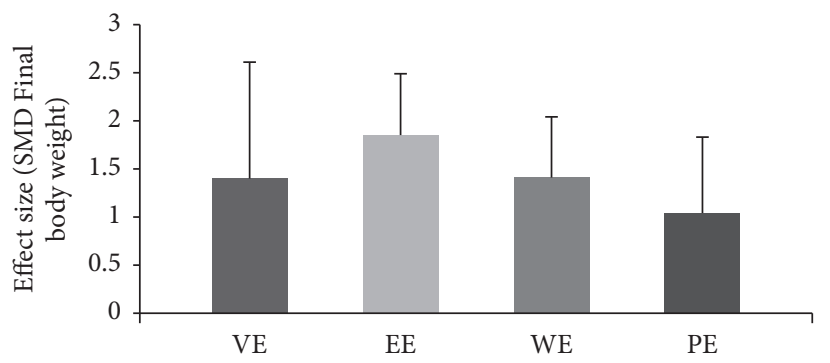

(e)

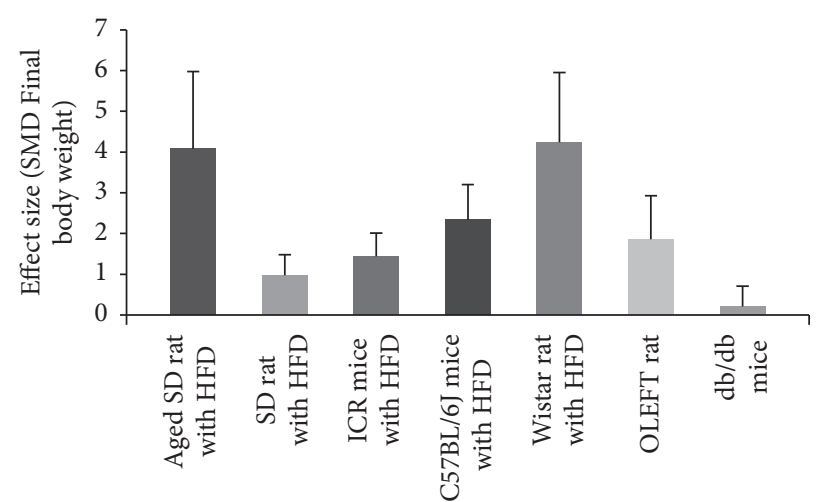

(b)

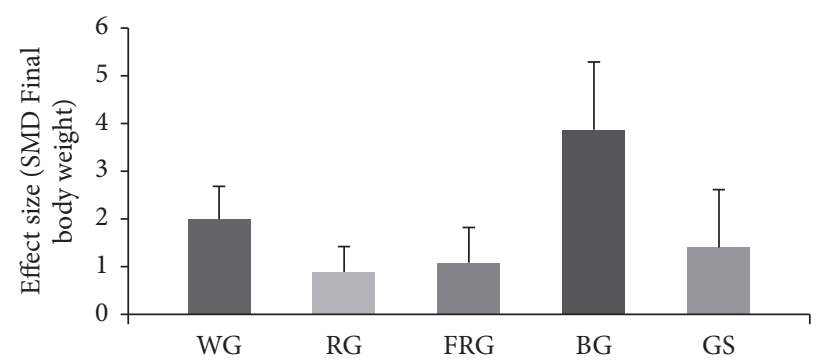

(d)

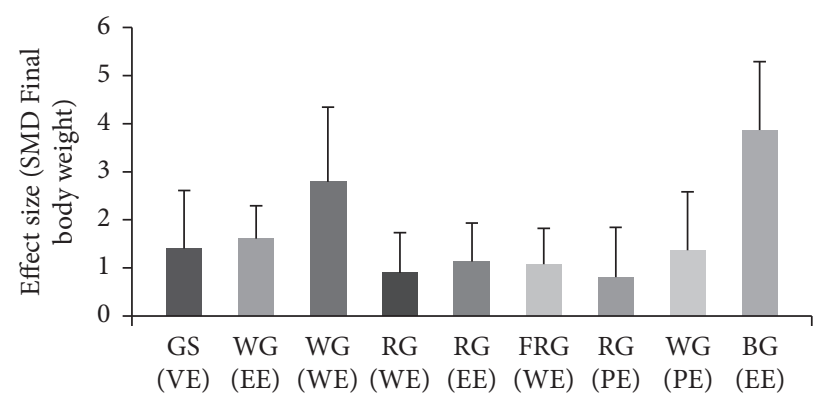

(f)

FIGURE 6: Estimated effect size of body weight between treatment and control groups stratified by (a) environmental/genetic model, (b) animal obesity model, (c) duration of intervention, (d) ginseng processing method, (e) ginseng extraction method, and ( $f$ ) type of ginseng. SMD: standard mean difference, wk: week, FRG: fermented red ginseng, RG: red ginseng, BG: black ginseng, GS: ginsam (vinegar extracted ginseng), WG: white ginseng, EE: ethanol extracted, WE: water extracted, PE: high-pressure extracted, P: powdered, and VE: vinegar extracted.

of the experimental groups was significantly lower than that of the control groups (SMD $=-36.64,95 \% \mathrm{CI}=-39.96$ to -33.31; $P<0.00001)$, with considerable heterogeneity $\left(I^{2}=\right.$ $\left.99 \%, \chi^{2}=2448.74, P<0.00001\right)$ (Figure 10).

3.4. Publication Bias. The risk of publication bias is depicted on a funnel plot (Figure 11). The asymmetry observed in the graph may indicate the presence of publication bias. Studies reporting a negative treatment effect tend not to be published or may be selectively reported. Furthermore, as the funnel plot is based on SMD, the results can be skewed.

One characteristic of animal studies is small sample size per group, which could influence the outcomes of included studies as the size of the overall effect can be over- or underestimated.

\section{Discussion}

This review describes the experimental details of $P$. ginseng administration (including dose, duration, and processing and extraction method) in studies using different species and strains of animals. Variations in these procedures might have contributed to the heterogeneity in treatment outcome observed between the studies. Subgroup analysis was therefore conducted. Effect size was found to vary according to type of ginseng, animal model, and duration of administration.

First, the processing method might have influenced the treatment effect. The compositions of active components of ginseng, such as ginsenosides, can differ considerably according to the extraction and processing method. For example, GS, a vinegar extract of $P$. ginseng, differs from regular white 


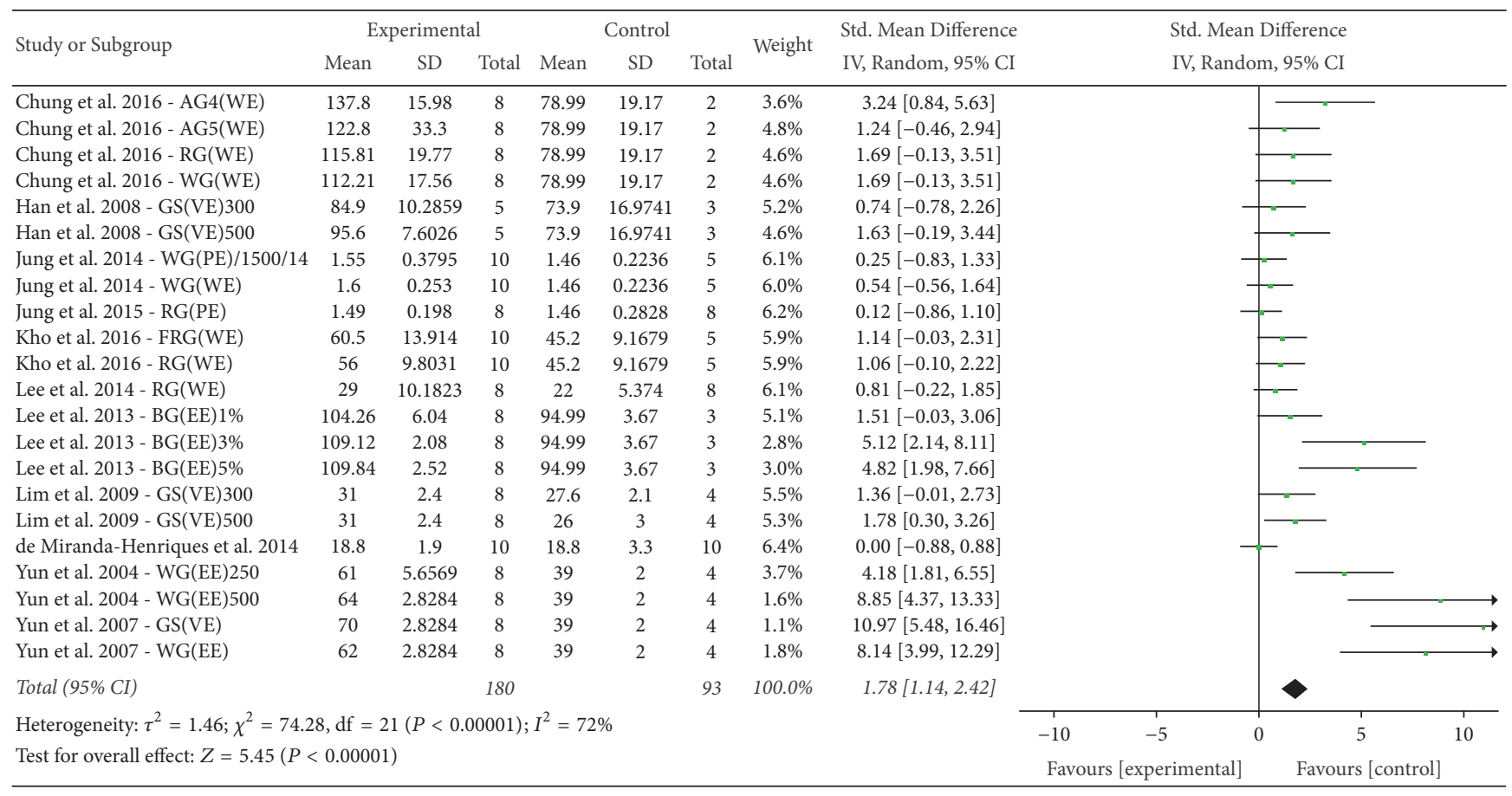

FIGURE 7: Forest plot comparing serum HDL between the treatment and control groups. AG4: 4-year-old ginseng, FRG: fermented red ginseng, RG: red ginseng, BG: black ginseng, GS: ginsam (vinegar extracted ginseng), WG: white ginseng, EE: ethanol extracted, WE: water extracted, PE: high-pressure extracted, P: powdered, and VE: vinegar extracted.

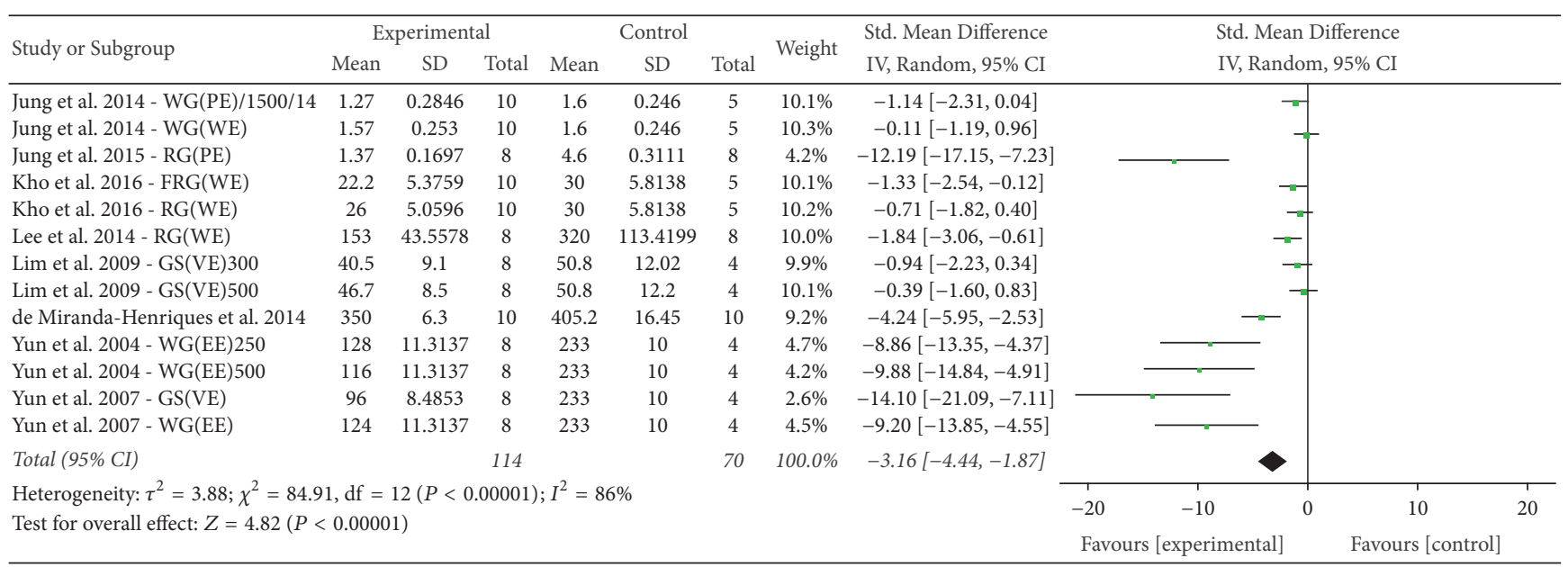

FIGURE 8: Forest plot comparing serum LDL between the treatment and control groups. AG4: 4-year-old ginseng, FRG: fermented red ginseng, RG: red ginseng, BG: black ginseng, GS: ginsam (vinegar extracted ginseng), WG: white ginseng, EE: ethanol extracted, WE: water extracted, PE: high-pressure extracted, P: powdered, and VE: vinegar extracted.

ginseng in ginsenoside concentration and exerts a greater effect on metabolic syndrome [59]. In this study, BG exerted the greatest effect among the interventions on inhibition of weight gain. BG, which is prepared from raw $P$. ginseng by nine cycles of steaming at $98^{\circ} \mathrm{C}$ for 3 hours followed by drying, exerted a higher biological activity than red ginseng or white ginseng [61]. However, in this review, the extraction method of ginseng did not significantly influence heterogeneity or treatment effect.
Second, the type of animal model of obesity was shown to influence heterogeneity, indicating that $P$. ginseng has a potential role in preventing weight gain induced by HFD. In contrast, $P$. ginseng had no significant effect in $\mathrm{db} / \mathrm{db}$ mice, which are a leptin receptor-deficient model characterized by marked hyperglycemia, hyperphagia, and reduced energy expenditure [34]. In studies using $\mathrm{db} / \mathrm{db}$ mice, ginseng exerted no significant effect on BW but did modulate plasma glucose level, insulin resistance, plasma adiponectin level, 


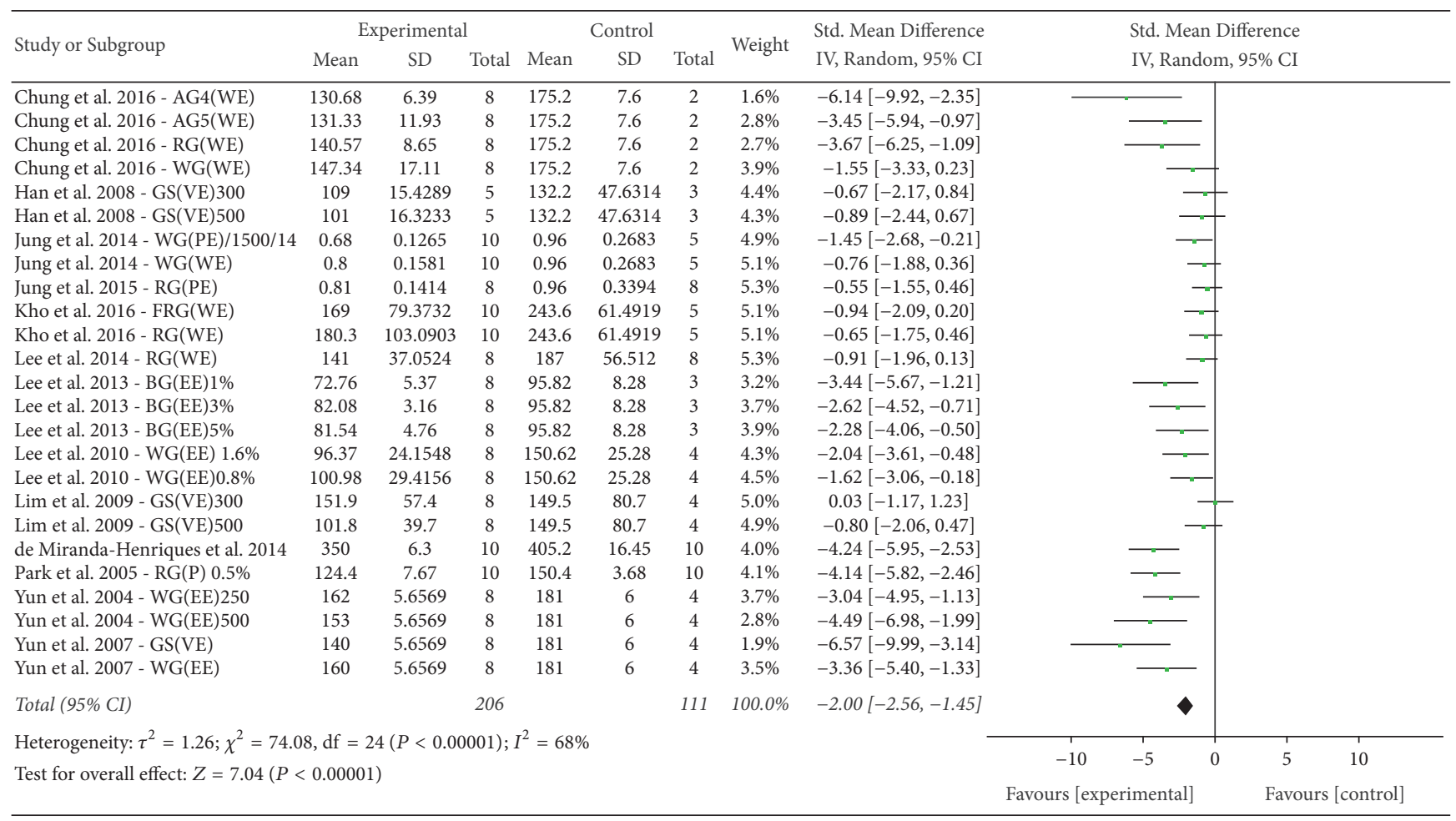

FIGURE 9: Forest plot comparing serum TG between the treatment and control groups. AG4: 4-year-old ginseng, FRG: fermented red ginseng, RG: red ginseng, BG: black ginseng, GS: ginsam (vinegar extracted ginseng), WG: white ginseng, EE: ethanol extracted, WE: water extracted, PE: high-pressure extracted, P: powdered, and VE: vinegar extracted.

and AMPK activity [46, 47, 57]. Ginseng thus has a significant effect on insulin sensitivity and may exert preventive and treatment effects in type 2 diabetes and hyperglycemia in $\mathrm{db} / \mathrm{db}$ mice despite the absence of a significant effect on weight loss. However, this outcome is inconsistent with the results of some previous studies [62]. Given that the number of studies included in this analysis was small, the possibility cannot be ruled out that the dosage or duration of ginseng administration of included studies was not large enough to demonstrate a significant treatment effect.

The duration of the intervention was also found to be a major cause of heterogeneity. More than half of the studies had an intervention period of 8 weeks. One study with an 11week intervention period showed that the greatest difference in BW between the control group and the experimental group was at 8 weeks [51]. The subgroup analysis was therefore conducted based on an 8-week treatment period. However, no significant difference in treatment effect and heterogeneity was observed.

Unexpectedly, the duration of intervention and extraction method did not significantly affect the magnitude of the treatment effect. Unlike meta-analyses of clinical studies, sources of bias and heterogeneity are not independent in meta-analyses of animal studies. Further studies are therefore required to determine the effects of administration period on treatment outcome.

Despite being generally considered a major cause of heterogeneity, subgroup analysis according to ginseng dose was not performed. Several previous studies have reported dose-dependent effects of ginseng $[53,58]$. However, studies included in this review used different units of dosage, such as $\mathrm{mg} / \mathrm{kg}$ (body weight), $\mathrm{mg} / \mathrm{kg}$ (food intake), \% (density), or $\mathrm{mg} /$ day. Furthermore, depending on the extraction or processing method, the quantity of active substance can differ even at the same dose $[45,50,51]$. Therefore, the actual administered dose cannot be regarded as equivalent where the same dose is given but processing or extraction method differs. These factors limit the ability to stratify groups based on dose. Therefore, subgroup analysis according to ginseng dose was not performed, despite its importance.

To date, various hypotheses have been suggested to explain the mechanisms underlying the antiobesity effects of $P$. ginseng. Ginseng is reported to affect appetite and the levels of related hormones including leptin, adiponectin, and ghrelin. It also attenuates HFD-induced chronic inflammation of the hypothalamus, improving leptin resistance and reducing the secretion of neuropeptide Y [53, 59]. Furthermore, it is suggested that ginseng inhibits the digestion and absorption of carbohydrate and fat by inhibiting the activity of pancreatic lipase, and reports of reduced blood glucose and increased fecal weight support this hypothesis [18, 53]. Ginseng may also exert an antiadipogenic effect and increase fat oxidation and energy expenditure by regulating PAR- $\gamma / \mathrm{C} / \mathrm{EBP}-\alpha$, AMPK, and PPAR- $\alpha[17,21,22,27]$. The results of several studies are contradictory, so these proposed mechanisms remain controversial. 


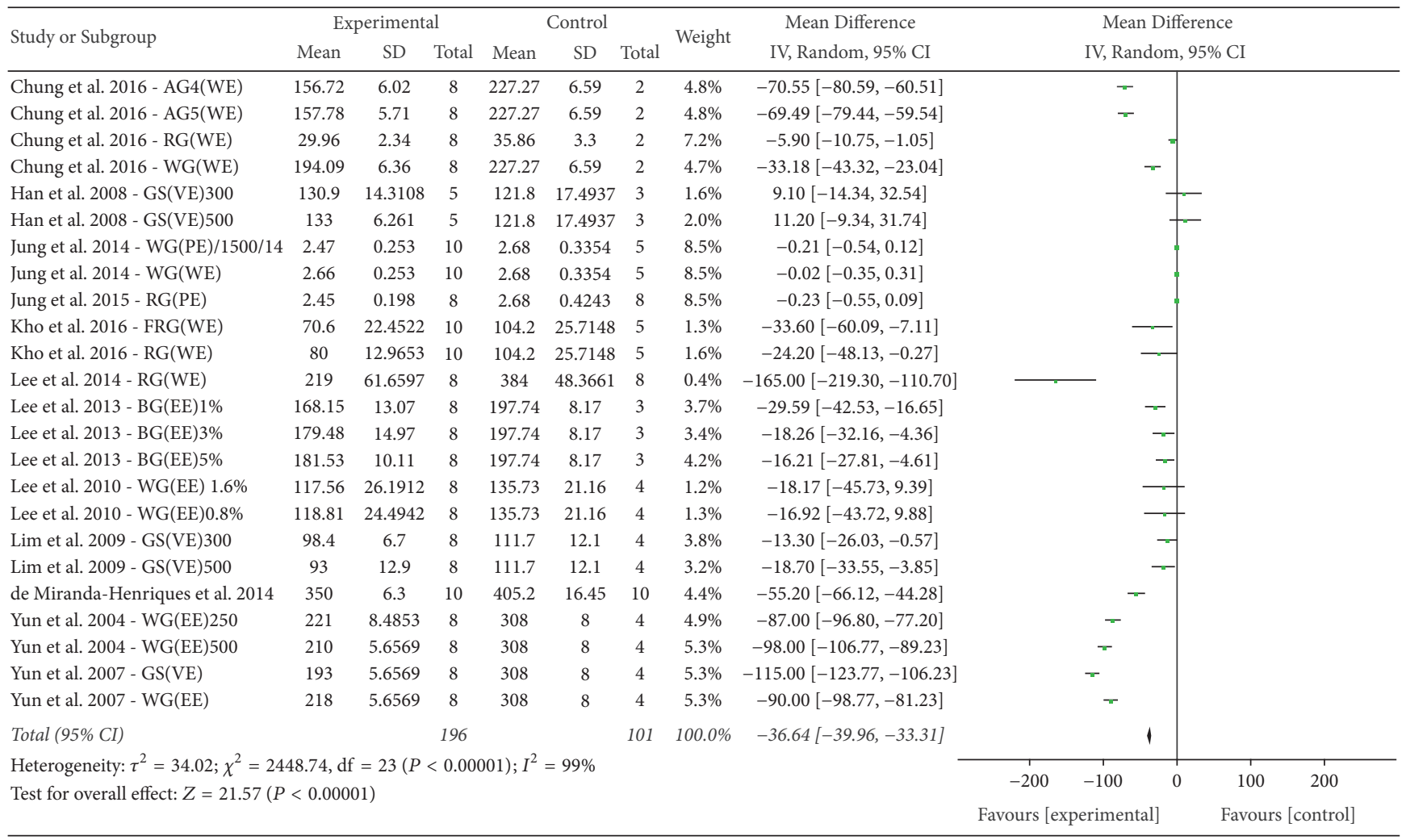

FIGURE 10: Forest plot comparing serum TC between the treatment and control groups. AG4: 4-year-old ginseng, FRG: fermented red ginseng, RG: red ginseng, BG: black ginseng, GS: ginsam (vinegar extracted ginseng), WG: white ginseng, EE: ethanol extracted, WE: water extracted, PE: high-pressure extracted, P: powdered, and VE: vinegar extracted.

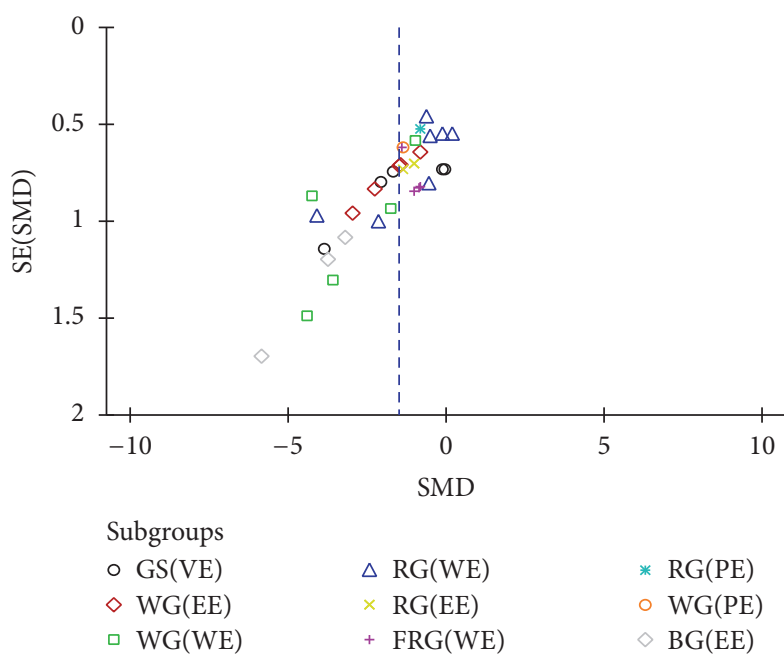

FIGURE 11: Funnel plot for publication bias FRG: fermented red ginseng, RG: red ginseng, BG: black ginseng, GS: ginsam (vinegar extracted ginseng), WG: white ginseng, EE: ethanol extracted, WE: water extracted, PE: high-pressure extracted, P: powdered, and VE: vinegar extracted.

To our knowledge, this is the first systematic review and meta-analysis of the antiobesity effect of $P$. ginseng in animal experiments. Our findings indicate that $P$. ginseng inhibits weight gain in animal obesity models and that LDL, TG, and TC were significantly lower in ginseng-treated groups than in control groups, while HDL was significantly higher. P. ginseng can therefore be considered to exert a positive effect on improving serum lipid profiles. There were some limitations to our review, however. The total number of studies and the sample size were too small for the results to be considered reliable. Furthermore, there was a risk of publication bias, given that studies reporting negative results tend to remain unpublished, thus contributing to an overestimation of the effect size. The inclusion of articles written only in English might also have caused a language bias. In general, the quality of included studies was low because of the poor reporting, which is a common feature of animal studies. Despite the fact that the risk of bias has been increasingly emphasized in animal studies, reporting experimental details is still very insufficient in most animal studies [60]. This might have had a significant impact on the outcome of the metaanalysis. Further well-designed and well-reported studies on antiobesity effects in animal models are therefore required.

Although multiple studies on the antiobesity effects of $P$. ginseng in animals have been published to date, relatively few clinical trials in humans have been reported and are limited by the absence of placebo, small sample size, and an overly specific study population $[17,24,25]$. Therefore, this systematic analysis of experimental studies was necessary to evaluate feasibility prior to conducting future clinical trials. 
The information reported in our review may contribute significantly to the information required for transitioning from preclinical studies to clinical trials $[26,63]$. Additional studies and the verification of outcomes using longitudinal human studies are therefore required to elucidate the antiobesity effects of ginseng in humans. Before conducting clinical trials, however, an appropriate dosage and treatment period to show a significant treatment effect should be established. These parameters may differ according to the ginseng processing or extraction method, or the cause of obesity, whether innate or acquired.

\section{Conclusions}

(1) P. ginseng administration significantly inhibits weight gain in animal obesity models.

(2) The processing method of ginseng may cause differences in the observed antiobesity effects, although there is insufficient evidence that the duration of administration and ginseng extraction method may affect the outcome.

(3) The treatment effect was higher in animal obesity models induced by HFD than in genetic $\mathrm{db} / \mathrm{db}$ models.

(4) The administration of $P$ ginseng may significantly lower the serum TC, TG, and LDL levels but may elevate the serum HDL level.

(5) Sample sizes of included studies were generally small, and the risk of bias was generally low as a result of poor reporting. Further well-designed and wellreported studies are therefore needed.

(6) Further clinical studies should be conducted to verify the antiobesity effects of ginseng in humans, with consideration given to dose, treatment period, and ginseng processing method during study design.

\section{Conflicts of Interest}

The authors declare that there are no conflicts of interest regarding the publication of this paper.

\section{References}

[1] M. Ng, T. Fleming, M. Robinson et al., "Global, regional and national prevalence of overweight and obesity in children and adults 1980-2013," The Lancet, vol. 384, no. 9945, pp. 766-781, 2014.

[2] E. J. Nejat, A. J. Polotsky, and L. Pal, "Predictors of chronic disease at midlife and beyond - the health risks of obesity," Maturitas, vol. 65, no. 2, pp. 106-111, 2010.

[3] D. Aune, A. Sen, M. Prasad et al., "BMI and all cause mortality: Systematic review and non-linear dose-response meta-analysis of 230 cohort studies with 3.74 million deaths among 30.3 million participants," BMJ, vol. 353, Article ID i2156, 2016.

[4] W. V. Brown, K. Fujioka, P. W. F. Wilson, and K. A. Woodworth, "Obesity: Why be concerned?" American Journal of Medicine, vol. 122, no. 4, pp. S4-S11, 2009.
[5] J. P. H. Wilding, "Medication use for the treatment of diabetes in obese individuals," Diabetologia, pp. 1-8, 2017.

[6] S. Klobučar Majanović, Ž. Crnčević Orlić, and D. Štimac, "Current trends in the pharmacotherapy for obesity," Endocrine Oncology and Metabolism, vol. 2, no. 1, pp. 50-59, 2016.

[7] S. Hasani-Ranjbar, Z. Jouyandeh, and M. Abdollahi, "A systematic review of anti-obesity medicinal plants-an update," Journal of Diabetes and Metabolic Disorders, vol. 12, no. 1, article 28, 2013.

[8] J. W. Yun, "Possible anti-obesity therapeutics from nature-a review," Phytochemistry, vol. 71, no. 14-15, pp. 1625-1641, 2010.

[9] T. K. Yun, "Brief introduction of Panax ginseng C.A. Meyer," Journal of Korean Medical Science, vol. 16, pp. S3-S5, 2001.

[10] D. Dai, C.-F. Zhang, S. Williams, C.-S. Yuan, and C.-Z. Wang, "Ginseng on Cancer: Potential Role in Modulating Inflammation-Mediated Angiogenesis," American Journal of Chinese Medicine, vol. 45, no. 1, pp. 13-22, 2017.

[11] C. H. Lee and J.-H. Kim, "A review on the medicinal potentials of ginseng and ginsenosides on cardiovascular diseases," Journal of Ginseng Research, vol. 38, no. 3, pp. 161-166, 2014.

[12] E. Shishtar, J. L. Sievenpiper, V. Djedovic et al., "The effect of ginseng (The Genus Panax) on glycemic control: A systematic review and meta-analysis of randomized controlled clinical trials," PLoS ONE, vol. 9, no. 9, Article ID e107391, 2014.

[13] A. S. Braz, L. C. S. Morais, A. P. Paula, M. F. F. M. Diniz, and R. N. Almeida, "Effects of Panax ginseng extract in patients with fibromyalgia: A 12-week, randomized, double-blind, placebocontrolled trial," Revista Brasileira de Psiquiatria, vol. 35, no. 1, pp. 21-28, 2013.

[14] V. Rastogi, J. Santiago-Moreno, and S. Doré, "Ginseng: a promising neuroprotective strategy in stroke," Frontiers in Cellular Neuroscience, vol. 8, article 457, 2015.

[15] H.-G. Kim, J.-H. Cho, S.-R. Yoo et al., "Antifatigue effects of Panax ginseng C.A. Meyer: a randomised, double-blind, placebo-controlled trial," PLOS ONE, vol. 8, no. 4, Article ID e61271, 2013.

[16] L.-K. Han, Y. Kimura, M. Kawashima et al., "Anti-obesity effects in rodents of dietary teasaponin, a lipase inhibitor," International Journal of Obesity, vol. 25, no. 10, pp. 1459-1464, 2001.

[17] Z. Li and G. E. Ji, "Ginseng and obesity," Journal of Ginseng Research, 2017.

[18] N. Karu, R. Reifen, and Z. Kerem, "Weight gain reduction in mice fed Panax ginseng saponin, a pancreatic lipase inhibitor," Journal of Agricultural and Food Chemistry, vol. 55, no. 8, pp. 2824-2828, 2007.

[19] J. H. Kim, D. H. Hahm, D. C. Yang, J. H. Kim, H. J. Lee, and I. Shim, "Effect of crude saponin of Korean red ginseng on highfat diet-induced obesity in the rat," Journal of Pharmacological Sciences, vol. 97, no. 1, pp. 124-131, 2005.

[20] J. H. Kim, S. A. Kang, S.-M. Han, and I. Shim, "Comparison of the antiobesity effects of the protopanaxadiol- and protopanaxatriol-type saponins of red ginseng," Phytotherapy Research, vol. 23, no. 1, pp. 78-85, 2009.

[21] J.-T. Hwang, S.-H. Kim, M.-S. Lee et al., "Anti-obesity effects of ginsenoside $\mathrm{Rh} 2$ are associated with the activation of AMPK signaling pathway in 3T3-L1 adipocyte," Biochemical and Biophysical Research Communications, vol. 364, no. 4, pp. 10021008, 2007.

[22] J. Hwang, M. Lee, H. Kim et al., " Antiobesity effect of ginsenoside Rg3 involves the AMPK and PPAR- ," Phytotherapy Research, vol. 23, no. 2, pp. 262-266, 2009. 
[23] Y.-B. Song, Y. R. An, S. J. Kim et al., "Lipid metabolic effect of Korean red ginseng extract in mice fed on a high-fat diet," Journal of the Science of Food and Agriculture, vol. 92, no. 2, pp. 388-396, 2012.

[24] D. H. Kwon, S. Bose, M. Y. Song et al., "Efficacy of Korean red ginseng by single nucleotide polymorphism in obese women: Randomized, double-blind, placebo-controlled trial," Journal of Ginseng Research, vol. 36, no. 2, pp. 176-189, 2012.

[25] M. Y. Song, B. S. Kim, and H. Kim, "Influence of Panax ginseng on obesity and gut microbiota in obese middle-aged Korean women," Journal of Ginseng Research, vol. 38, no. 2, pp. 106-115, 2014.

[26] M. Ritskes-Hoitinga, M. Leenaars, M. Avey, M. Rovers, and R. Scholten, "Systematic reviews of preclinical animal studies can make significant contributions to health care and more transparent translational medicine.", Cochrane Database of Systematic Reviews, vol. 3, p. ED000078, 2014.

[27] L. Zhang, C. Virgous, and H. Si, "Ginseng and obesity: observations and understanding in cultured cells, animals and humans," The Journal of Nutritional Biochemistry, vol. 44, pp. 1-10, 2017.

[28] F. M. Siraj, Y. J. Kim, S. Natarajan, S. K. Jung, D. U. Yang, and D. C. Yang, "Ginseng and obesity: Observations from assorted perspectives," Food Science and Biotechnology, vol. 23, no. 4, pp. 1007-1016, 2014.

[29] J. P. T. Higgins and S. Green, Cochrane Handbook for Systematic Reviews of Interventions, John Wiley \& Sons, 2011.

[30] C. Hooijmans, K. E. Wever, and R. B. M. de Vries, "SYRCLEs starting guide for systematic reviews of preclinical animal interventions studies, 2016," https://issuu.com/radboudumc/ docs/syrcle_starting_guide_tool? $\mathrm{e}=28355229 / 45970684$.

[31] D. Moher, A. Liberati, J. Tetzlaff, and D. G. Altman, "Preferred reporting items for systematic reviews and meta-analyses: the PRISMA statement," International Journal of Surgery, vol. 8, no. 5, pp. 336-341, 2010.

[32] K. J. Kaiyala and M. W. Schwartz, "Toward a more complete (and less controversial) understanding of energy expenditure and its role in obesity pathogenesis," Diabetes, vol. 60, no. 1, pp. $17-23,2011$.

[33] R. L. Leibel, "Molecular physiology of weight regulation in mice and humans," International Journal of Obesity, vol. 32, supplement 7, pp. S98-S108, 2008.

[34] T. A. Lutz and S. C. Woods, "Overview of animal models of obesity," Current Protocols in Pharmacology, pp. 5-61, 2012.

[35] M. R. Fernandes, N. V. de Lima, K. S. Rezende, I. C. M. Santos, I. S. Silva, and R. D. C. A. Guimarães, "Animal models of obesity in rodents. An integrative review," Acta Cirurgica Brasileira, vol. 31, no. 12, pp. 840-844, 2016.

[36] R. Buettner, J. Schölmerich, and L. C. Bollheimer, "High-fat diets: modeling the metabolic disorders of human obesity in rodents," Obesity, vol. 15, no. 4, pp. 798-808, 2007.

[37] J. Cho, K. Kim, H. Park, Y. Yoon, and M. Song, "Anti-Obesity Effect of Panax Ginseng in Animal Models: Study Protocol for a Systematic Review and Meta-Analysis," Journal of Korean Medicine for Obesity Research, vol. 17, no. 1, pp. 37-45, 2017.

[38] M. Leenaars, C. R. Hooijmans, N. van Veggel et al., "A step-bystep guide to systematically identify all relevant animal studies," Laboratory Animals, vol. 46, no. 1, pp. 24-31, 2012.

[39] R. B. M. de Vries, C. R. Hooijmans, A. Tillema, M. Leenaars, and M. Ritskes-Hoitinga, "A search filter for increasing the retrieval of animal studies in Embase," Laboratory Animals, vol. 45, no. 4, pp. 268-270, 2011.
[40] C. R. Hooijmans, A. Tillema, M. Leenaars, and M. RitskesHoitinga, "Enhancing search efficiency by means of a search filter for finding all studies on animal experimentation in PubMed," Laboratory Animals, vol. 44, no. 3, pp. 170-175, 2010.

[41] C. R. Hooijmans, M. M. Rovers, R. B. M. De Vries, M. Leenaars, M. Ritskes-Hoitinga, and M. W. Langendam, "SYRCLE's risk of bias tool for animal studies," BMC Medical Research Methodology, vol. 14, no. 1, article no. 43, 2014.

[42] J. P. Higgin, S. G. Thompson, J. J. Deeks, and D. G. Altman, "Measuring inconsistency in meta-analysis," British Medical Journal, vol. 327, pp. 557-560, 2003.

[43] M. Egger, G. D. Smith, M. Schneider, and C. Minder, "Bias in meta-analysis detected by a simple, graphical test," British Medical Journal, vol. 315, pp. 629-634, 1997.

[44] H. M. Vesterinen, E. S. Sena, and K. J. Egan, "Meta-analysis of data from animal studies: a practical guide," Journal of Neuroscience Methods, vol. 221, pp. 92-102, 2014.

[45] S. I. Chung, S. J. Nam, M. Xu, M. Y. Kang, and S. C. Lee, "Aged ginseng (Panax ginseng Meyer) reduces blood glucose levels and improves lipid metabolism in high fat diet-fed mice," Food Science and Biotechnology, vol. 25, no. 1, pp. 267-273, 2016.

[46] E. J. Han, K. J. Park, S. K. Ko, and S. H. Chung, "A vinegarprocessed ginseng radix (Ginsam) ameliorates hyperglycemia and dyslipidemia in C57BL/KsJ db/db mice," Food Science and Biotechnology, vol. 17, no. 6, pp. 1228-1234, 2008.

[47] B. N. Hong, M. G. Ji, and T. H. Kang, "The Efficacy of Red Ginseng in Type 1 and Type 2 Diabetes in Animals," Evidence-Based Complementary and Alternative Medicine, vol. 2013, Article ID 593181, 7 pages, 2013.

[48] S. Jung, M.-S. Lee, Y. Shin et al., "Anti-obesity and antiinflammatory effects of high hydrostatic pressure extracts of ginseng in high-fat diet induced obese rats," Journal of Functional Foods, vol. 10, pp. 169-177, 2014.

[49] S. Jung, M.-S. Lee, Y. Shin, C.-T. Kim, I.-H. Kim, and Y. Kim, "High hydrostatic pressure extract of red ginseng attenuates inflammation in rats with high-fat diet induced obesity," Preventive Nutrition and Food Science, vol. 20, no. 4, pp. 253-259, 2015.

[50] M. C. Kho, Y. J. Lee, J. H. Park et al., "Fermented red ginseng potentiates improvement of metabolic dysfunction in metabolic syndrome rat models," Nutrients, vol. 8, no. 6, article 369, 2016.

[51] C. M. Kim, S. J. Yi, I. J. Cho, and S. K. Ku, "Red-koji fermented red ginseng ameliorates high fat diet-induced metabolic disorders in mice," Nutrients, vol. 5, no. 11, pp. 4316-4332, 2013.

[52] J. Lee, J.-Y. Cho, and W.-K. Kim, "Anti-inflammation effect of exercise and Korean red ginseng in aging model rats with dietinduced atherosclerosis," Nutrition Research and Practice, vol. 8, no. 3, pp. 284-291, 2014.

[53] M. R. Lee, B. C. Kim, R. Kim et al., "Anti-obesity effects of black ginseng extract in high fat diet-fed mice," Journal of Ginseng Research, vol. 37, no. 3, pp. 308-314, 2013.

[54] Y.-S. Lee, B.-Y. Cha, K. Yamaguchi et al., "Effects of Korean white ginseng extracts on obesity in high-fat diet-induced obese mice," Cytotechnology, vol. 62, no. 4, pp. 367-376, 2010.

[55] S. Lim, J. W. Yoon, S. H. Choi et al., "Effect of ginsam, a vinegar extract from Panax ginseng, on body weight and glucose homeostasis in an obese insulin-resistant rat model," Metabolism - Clinical and Experimental, vol. 58, no. 1, pp. 8-15, 2009.

[56] M. S. de Miranda-Henriques, M. D. F. F. D. M. Diniz, and M. S. T. de Araújo, "Ginseng, green tea or fibrate: Valid 
options for nonalcoholic steatohepatitis prevention?" Arquivos de Gastroenterologia, vol. 51, no. 3, pp. 255-260, 2014.

[57] M.-Y. Park, K.-S. Lee, and M.-K. Sung, "Effects of dietary mulberry, Korean red ginseng, and banaba on glucose homeostasis in relation to PPAR- $\alpha$, PPAR- $\gamma$, and LPL mRNA expressions," Life Sciences, vol. 77, no. 26, pp. 3344-3354, 2005.

[58] S. N. Yun, S. J. Moon, S. K. Ko, B. O. Im, and S. H. Chung, "Wild ginseng prevents the onset of high-fat diet induced hyperglycemia and obesity in ICR mice," Archives of Pharmacal Research, vol. 27, no. 7, pp. 790-796, 2004.

[59] S. N. Yun, S. K. Ko, K. H. Lee, and S. H. Chung, "Vinegarprocessed ginseng radix improves metabolic syndrome induced by a high fat diet in ICR mice," Archives of Pharmacal Research, vol. 30, no. 5, pp. 587-595, 2007.

[60] C. Kilkenny, N. Parsons, E. Kadyszewski et al., "Survey of the quality of experimental design, statistical analysis and reporting of research using animals," PLoS ONE, vol. 4, no. 11, Article ID e7824, 2009.

[61] L. Zhang, L. Zhang, X. Wang, and H. Si, "Anti-adipogenic effects and mechanisms of ginsenoside Rg3 in pre-adipocytes and obese mice," Frontiers in Pharmacology, vol. 8, article no. 113, 2017.

[62] H. Lee, M. Kim, S. Shik Shin, and M. Yoon, "Ginseng treatment reverses obesity and related disorders by inhibiting angiogenesis in female db/db mice," Journal of Ethnopharmacology, vol. 155, no. 2, pp. 1342-1352, 2014.

[63] P. Pound, S. Ebrahim, P. Sandercock, M. B. Bracken, and I. Roberts, "Where is the evidence that animal research benefits humans?" British Medical Journal, vol. 328, no. 7438, pp. 514$517,2004$. 


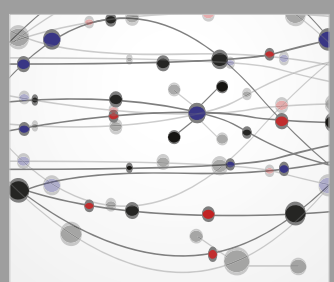

The Scientific World Journal
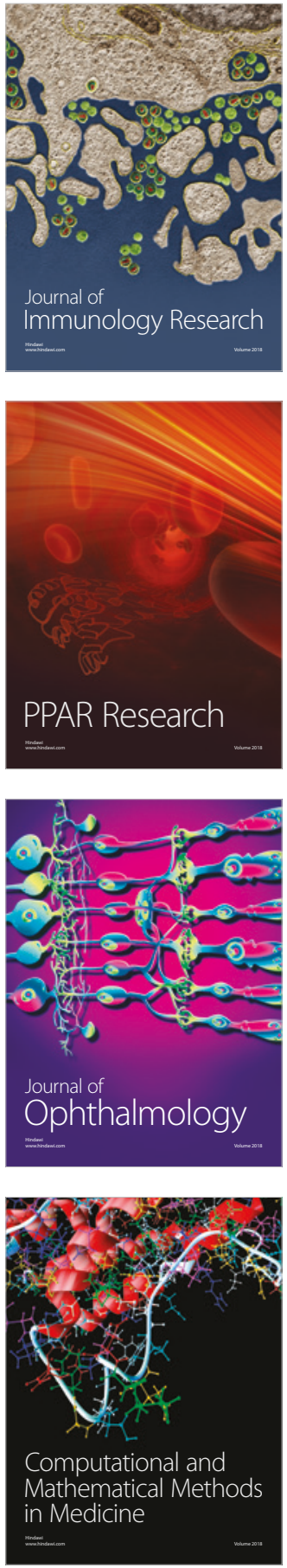

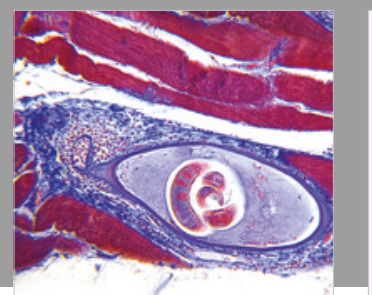

Gastroenterology Research and Practice

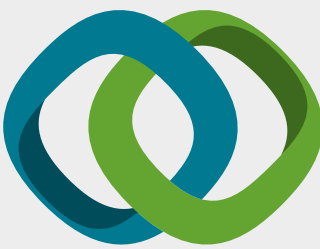

\section{Hindawi}

Submit your manuscripts at

www.hindawi.com
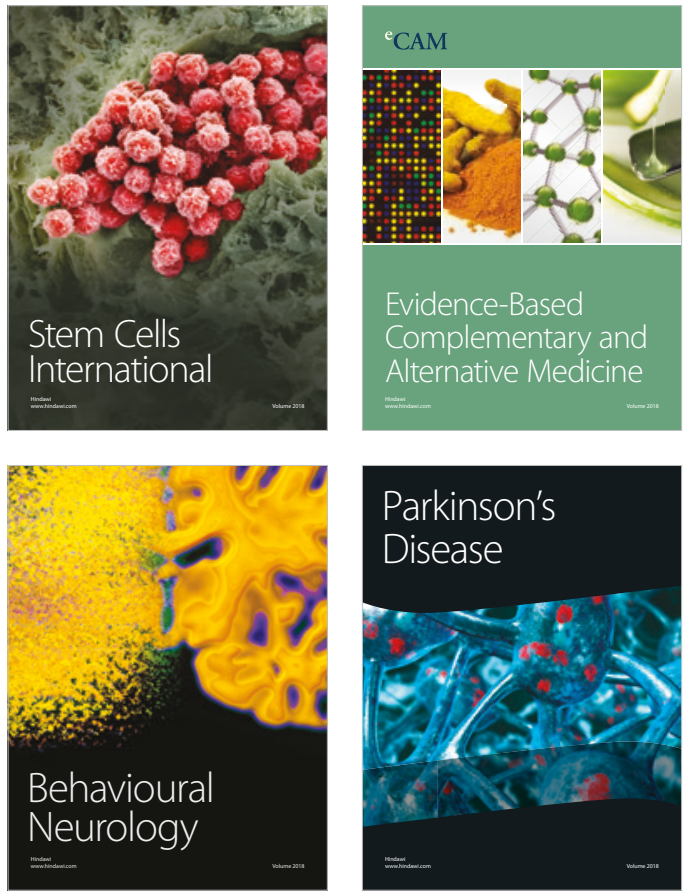

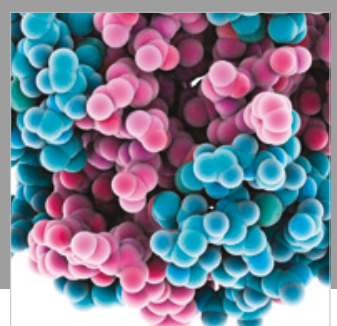

ournal of

Diabetes Research

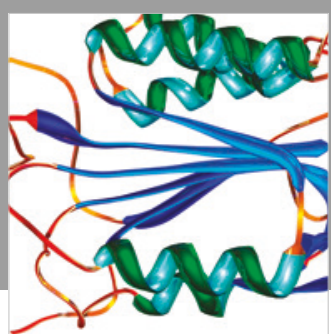

Disease Markers
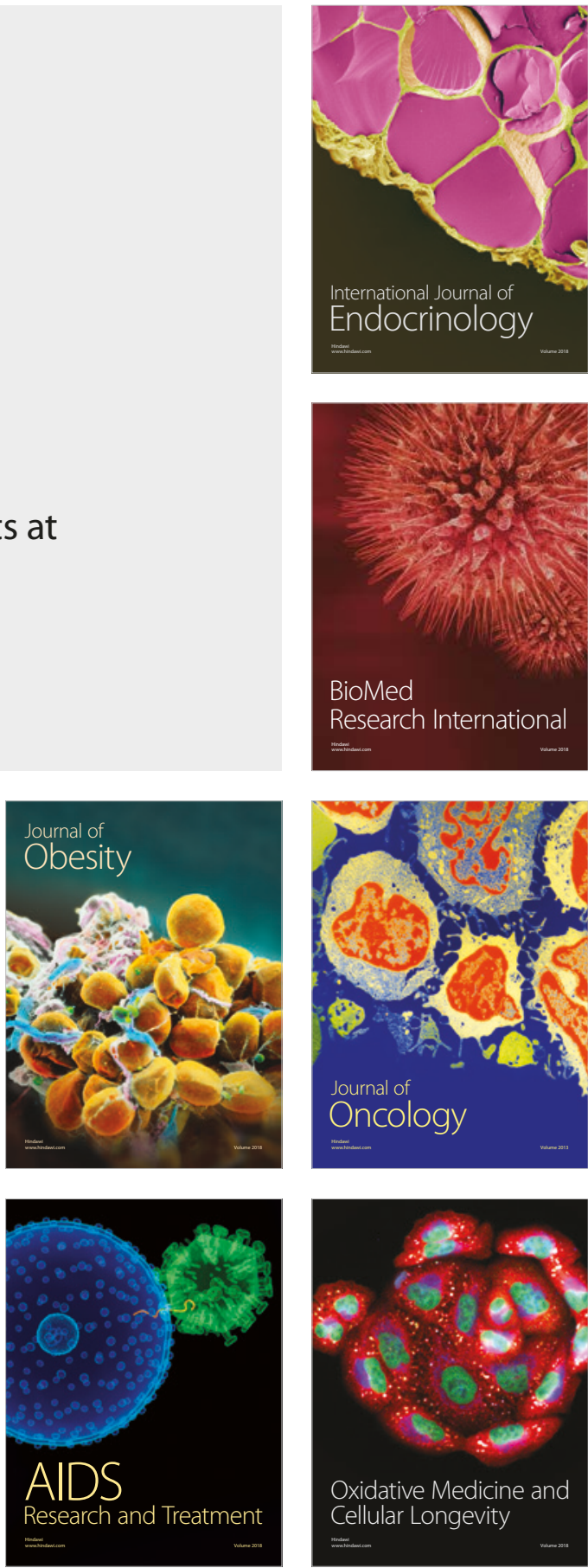